Received: 23/07/2018

Revision: 10/12/2018

Accepted: $15 / 12 / 2018$

OnlineFirst: 11/01/2019

\title{
Impact of Backward Design on Improving Iranian Advanced Learners' Writing Ability: Teachers' Practices and Beliefs
}

\section{Hossein Hosseini}

Ph.D Cadidate, Department of English, Isfahan (Khorasgan) Branch, Islamic Azad University, Isfahan, Iran, Hosseini7951@gmail.com

\section{Azizeh Chalak}

Assoc. Prof., Department of English, Isfahan (Khorasgan) Branch, Islamic Azad University, Isfahan, Iran, azizeh_chalak@yahoo.com

\section{Reza Biria}

Assoc. Prof., Department of English, Isfahan (Khorasgan) Branch, Islamic Azad University, Isfahan, Iran, biria_reza@yahoo.com

\begin{abstract}
The purpose of this study was twofold. First, it aimed to determine whether the application of backward design model has any significant effect on improving the writing ability of Iranian intermediate EFL learners. Second, the study sought to evaluate the superiority of backward design to conventional forward models in the improvement of the writing ability of Iranian EFL learners. The study population was 100 Iranian EFL learners chosen through the administered Quick Placement Test (QPT) in Gooyesh Language Institute, Isfahan, Iran. Based on the results of the test, they were randomly assigned to two samples (50 each); namely, the control and experimental groups. During the treatment, the control group received the writing instruction through a conventional method of forward design, while the participants in the experimental group were taught by the backward design. Both control and experimental samples were homogenized based on learners' responses to one version of IELTS Writing Task 1 used as the pre-test. At the end of the treatment the same task which was used as the pre-test task was also used as the post-test task to measure the improvement of the writing ability of both groups. The results of data analysis showed that backward design teaching approach failed to be more effective than traditional instruction as far as L2 writing ability of Iranian EFL learners was concerned. Furthermore, backward design teaching approach was pedagogically and significantly superior to conventional forward models in the improvement of Iranian EFL learners' writing ability.
\end{abstract}

Keywords: backward design, curriculum, forward design, understanding, writing ability

Citation: Hosseini, H., Chalak, A., \& Biria, R.. (2019). Impact of Backward Design on Improving Iranian Advanced Learners' Writing Ability: Teachers' Practices and Beliefs. International Journal of Instruction, 12(2), 33-50. https://doi.org/10.29333/iji.2019.1223a 


\section{INTRODUCTION}

Language is a tool for communication. Wittegenstein indicates that 'Communication is the foundation of all social life (as cited in Hall, 2002, p.2). In communicative activity, each individual brings their own linguistic resources and social identities with them. These linguistic resources could be interpreted and understood via social and cultural contexts. Linguistic resources, social identities, and socio-cultural contexts help identify the goals to accomplish a communicative activity (Hall, 2002, p.7).

Writing is one of the main skills required to start communication in any language, especially for non-native speakers. Foreign language learners' speech then is based on the process of trial and error. Therefore, writing is a complex skill; it relies on making efforts and practice. The significance of writing is stressed by many researchers $(\mathrm{Li}$, 2012; Choi, 2013; Olanezhad, 2015) who assured the crucial role that writing has played in the history of mankind. Writing provides people with a means to communicate their feelings, achievements, dreams, and opinions. Brown (2001) said that: "Writing is a thinking process; a writer produces a final written product based on their thinking after the writer goes through the thinking process. Writing allows us to analyse and expand on what we know and it promotes meta-cognition. Later, in the 1980s, ESL writing moved from a product-based approach to the process approach (Onozawa, 2010)"'.

Curriculum development is more than a bulleted list or prescribed format mandated by textbook publishers or curriculum maps published by school districts. It is more than words in theory with little practical application. It cannot be succinctly defined, developed, and packaged. Instead, curriculum development is an intricate process which requires deep thought and consideration. Macdonald and Purpel (1987) suggested that curriculum considers the "visions of humanity, the universe, human potential, and relationships to the cosmos" (p.192). According to Henderson and Gornik (2007) curriculum development resulted from employing "problem-solving processes" with a critical and reflective eye. Bobbitt (2004) defined curriculum as a "series of things which children and youth must do and experience by way of developing abilities to do things well that make up the affairs of adult life; and to be in all respects what adults should be" (p. 11).

Today, curriculum development is slowly beginning to emerge from the shadows of the Tyler Rationale. A new paradigm encompasses a shift towards a more scientific and transformative (Bobbitt, 2004; Henderson \& Gornik, 2007) curriculum. Within this stance, curriculum development carefully considers the multifaceted nature of student needs to thrive in an evolving world (Schwab, 1969). During this time of modern curriculum development, the task does not lie in simply repeating the old curriculum, but in embracing the "now" (Pinar, 2006, p. 12). The 'now' (Pinar, 2006, p. 12) consists of complexities that characterize students socially and intellectually. Transformative curriculum repurposes education to develop a student's conceptual understanding that lasts beyond a standardized assessment (Danielson, 1996). However, before any curriculum work commences, Pinar (2006) stated that the empowerment of teachers to make decisions that change the face of curriculum is paramount to the new shift in curriculum development. Identifying learning outcomes or objectives is often seen to 
depend upon a systematic analysis of the learners' communicative needs, and emerged in the 1960s as part of the systems approach to curriculum development - an aspect of the prevalent philosophy of educational accountability from which the use of objectives was also derived (Stufflebeam et al., 1985).

UbD is a model of planning that was championed by Wiggins and McTighe (1998) as a method of intentional planning in education. At its core, UbD has three main stages: (a) Identify the desired results, (b) determine the desired evidence, and (c) plan instruction and experiences to meet the results (Florian \& Zimmerman, 2015). Hinchliffe (2016) summarize UbD model in a few words; "When we truly understand, we can explain, can interpret, can apply, have perspective, can empathize, and have self-knowledge". McTighe (2013) refers to the benefits of using UbD model in the educational process, which are: Provide structured, yet flexible frameworks for guiding curriculum planning, instruction, and assessment aligned to standards.

The Understanding by Design framework ( $\mathrm{UbD}^{\mathrm{TM}}$ framework) offers a planning process and structure to guide curriculum, assessment, and instruction. Its two key ideas are contained in the title: 1) focus on teaching and assessing for understanding and learning transfer, and 2) design curriculum "backward" from those ends.

The UbD framework is based on seven key tenets:

1. Learning is enhanced when teachers think purposefully about curricular planning. The UbD framework helps this process without offering a rigid process or prescriptive recipe.

2. The UbD framework helps for curriculum and teaching focus on the development and deepening of student understanding and transfer of learning (i.e., the ability to effectively use content knowledge and skill).

3. Understanding is revealed when students autonomously make sense of and transfer their learning through authentic performance. Six facets of understanding - the capacity to explain, interpret, apply, shift perspective, empathize, and self-assess - can serve as indicators of understanding.

4. Effective curriculum is planned backward from long-term, desired results through a three-stage design process (Desired Results, Evidence, and Learning Plan). This process helps avoid the common problems of treating the textbook as the curriculum rather than a resource, and activity-oriented teaching in which no clear priorities and purposes are apparent.

5. Teachers are coaches of understanding, not mere purveyors of content knowledge, skill, or activity. They focus on ensuring that learning happens, not just teaching (and assuming that what was taught was learned); they always aim and check for successful meaning making and transfer by the learner.

6. Regularly reviewing units and curriculum against design standards enhances curricular quality and effectiveness, and provides engaging and professional discussions. 
7. The UbD framework reflects a continual improvement approach to student achievement and teacher craft. The results of our designs - student performanceinform needed adjustments in curriculum as well as instruction so that student learning is maximized. The Understanding by Design framework is guided by the confluence of evidence

In the past years, the backward design has turned into a well-established tradition in curriculum design particularly in general education and now it has re-emerged as a prominent curriculum approach in language teaching (Richard, 2013). Interestingly, backward design starts with the end task (assessment) and objectives in mind. In fact, it suggests that teachers should start with what the students are supposed to get out of instruction, that is, the skills and core objectives they need to fulfill, and as a result, the teachers have to figure out how they are going to actualize such instructional purposes to the best of their abilities.

Backward design is a great way to bring in the real world knowledge and resources that will really engage your students. It allows math teachers to bring in writing and English teachers to bring in data and charts. Using backward design can help teachers to create thematic units which can really help language teachers to create meaningful and engaging units so that students can experience a memorable learning. The best definition of backward design is that "The most successful teaching begins with clarity about desired learning outcomes and about the evidence that will show how learning has occurred" (Wiggins \&McTighe, 2011 , p. 7). Therefore, the main focus of interest in backward design has centered upon understanding, by which learners are prompted and encouraged much more for learning. This model makes the learners understand the goal of the process of learning better and causes them to reach those goals faster.

Wiggins and McTighe's backward design model is a three-stage approach which directly addresses Tyler's four questions about curriculum. In stage one, the desired results are identified and the purpose is determined. In stage two, acceptable evidence is determined; a means to evaluate the learning is identified. In stage three experiences and instruction are planned by selecting and organizing the most effective means to bring about the desired results (Howard, 2007).

Essentially, education has been associated with Forward Design beginning with syllabus planning, methodology, and finally ending with the assessment of learning outcomes. It is evident that resolving the issues of syllabus content and sequencing is considered as crucial starting points with Forward design, which has been the major tradition in language curriculum development. In this approach, understanding does not play a pivotal role. Based on an appropriate curriculum design, the teacher can help students to understand. However, if the curriculum is not appropriately designed, the instruction would be ineffective for developing learners' understanding (Childre, Sands, \& Tanner Pope, 2009). The reason is that many students fail to develop understanding of key concepts because the instruction focus is on textbooks, lectures, and worksheets that make learning relevant (Scruggs, Mastropier, \& McDuffie, 2007). 
With so many variables facing us in the classroom - the writing process, writing traits, writing rubrics, writing standards, writing workshops - how can we begin to put writing instruction in its proper perspective? I contend there is a missing link - a unifying structure - that is needed to help all writing teachers know what they should teach and why establishing a unifying structure helped us develop an effective writing curriculum in our own classrooms, as well as to create the Write Source handbooks and text series. We came to this structure through our own teaching experiences, our research into writing instruction, our discussions with other instructors, and our own writing. Once we had this structure in place, everything we did from planning to implementation fit easily - and meaningfully - within it. Our unifying structure consists of three major components. Essentially, all strategies, activities, and approaches in a well-conceived writing curriculum must promote:

»Fluency: opportunities for students to practice the act of writing

»Content: opportunities to develop meaningful writing

»Accuracy: opportunities to provide purposeful skill instruction when these three elements serve as the unifying structure of a curriculum, good things are going to happen.

Consequently, the idea of backward design was introduced into curriculum design under the aegis of "Understanding by Design" by McTighe and Wiggins (1998) who claim that the learning process should be planned with the final assessment in mind. In the past years, the backward design has turned into a well-established tradition in curriculum design particularly in general education, and now, it has re-emerged as a prominent curriculum approach in language teaching (Richards, 2013). Interestingly, backward design starts with the end task (assessment) and objectives in mind. In fact, it suggests that teachers should start with what the students are supposed to get out of instruction, that is, the skills and core objectives they need to fulfill, and as a result, the teachers have to figure out how they are going to actualize such instructional purposes to the best of their abilities. Therefore, the main focus of interest in backward design is centered upon understanding, by which learners are prompted and encouraged much more for learning. This model makes the learners understand the goal of the process of learning better and causes them to reach those goals faster.

Reviewing the available literature is replete with various studies investigating different factors influencing the teaching of productive skills including oral abilities; however, it seems that few have focused on the issue of backward design. On this basis, as an area of research which has not been fully considered especially in Iranian context the present study aimed to examine the extent to which a backward design of teaching writing ability can help intermediate EFL learners as well as the way they would perceive the utility of the new model compared with the conventional forward models of teaching oral abilities. So being an area of research which has not been fully considered especially in Iranian context of second language teaching, the impact of backward design on improving Iranian intermediate EFL learners' writing ability and on teachers' 
and learners' attitudes were investigated. Within this context, the following sub questions were tried to be answered:

1. Does backward design teaching approach improve the writing ability of Iranian EFL learners at an intermediate proficiency level?

2. Is backward design teaching approach pedagogically superior to conventional forward models in the improvement of productive skills of Iranian EFL learners at intermediate proficiency level?

\section{LITERATURE REVIEW}

\section{Forward Design}

Forward design is based on the assumption that input, process, and output are related in a linear fashion. In other words, before decisions about methodology and output are determined, issues related to the content of instruction need to be resolved. Curriculum design is seen to constitute a sequence of stages that occur in a fixed order - an approach that has been referred to as a 'waterfall' model (Tessmer and Wedman, 1990) where the output from one stage serves as the input to the stage that follows. This approach is described in Richards and Rodgers (2001:143-44), summarizing Docking (1994):

the traditional approach to developing a syllabus involves using one's understanding of subject matter as the basis for syllabus planning. One starts with the field of knowledge that one is going to teach (e.g. contemporary European history, marketing, listening comprehension, or French literature) and then selects concepts, knowledge, and skills that constitute that field of knowledge. A syllabus and the course content are then developed around the subject. Objectives may also be specified, but these usually have little role in teaching or assessing of the subject. Assessment of students is usually based on norm referencing, that is, students will be graded on a single scale with the expectation that they spread across a wide range of scores. Wiggins and McTighe (2006:15) give an illustration of this process with an example of a typical forward-design lesson plan:

- The teacher chooses a topic for a lesson (e.g. racial prejudice)

- The teacher selects a resource (e.g. To Kill a Mocking-bird)

- The teacher chooses instructional methods based on the resource and the topic (e.g. a seminar to discuss the book and cooperative groups to analyze stereotypical images in films and on television)

- The teacher chooses essay questions to assess student understanding of the book.

\section{Backward Design}

The third approach to curriculum design is to begin with a specification of learning outputs and to use these as the basis for developing instructional processes and input. Following Wiggins and McTighe (2006) and continuing with the analogy of forward and central design used above, the term backward design will be used to describe this approach. Backward design starts with a careful statement of the desired results or outcomes: appropriate teaching activities and content are derived from the results of 
learning. This is a well-established tradition in curriculum design in general education and in recent years has re-emerged as a prominent curriculum development approach in language teaching. It was sometimes described as an 'ends-means' approach, as seen in the work of Tyler (1949) and Taba (1962), who viewed instruction as the specification of ends as a pre-requite to devising the means to reach them. The process consists of:

Assessment

Content

Outcomes

TEACHING

Interaction between Elements of a Central Design

Step 1: diagnosis of needs

Step 2: formulation of objectives

Step 3: selection of content

Step 4: organization of content

Step 5: selection of learning experiences

Step 6: organization of learning experiences

Step 7: determination of what to evaluate and of the ways of doing it (Taba, 1962: 12).

The role of methodology was to determine which teaching methods were most effective in attaining the objectives and a criterion-referenced approach would be used for assessment. There is no place for individually-determined learning outcomes: the outcomes are determined by the curriculum designer.

A study conducted by Kelting-Gibson (2005) compared lesson and units designed using Backward Design (Wiggins \& McTighe, 2005) and those using traditional design. The study contained 59 participants, all pre-service teachers, from two sections of an undergraduate Educational Planning and Management course. The 59 participants produced a total of 153 lesson and unit plans. The study did not specify the number of participants in the control and experimental groups. Lesson and unit plans were evaluated using Danielson's (1996) six components essential to planning. Lesson and unit plans were scored as 1 = Unsatisfactory, 2 = Basic, $3=$ Proficient, and $4=$ Distinguished. Study results showed that the group that received instruction using Backward Design (Wiggins \& McTighe, 2005) outperformed those who received traditional curriculum instruction. Additionally, results indicated the experimental group displayed higher content knowledge, an ability to communicate criteria for assessments, a greater ability to set goals for students, an awareness of available resources, and greater performance when developing plans linked to instructional goals.

Stiler (2009) examined the usefulness of Backward Design (Wiggins \& McTighe, 2005) in an undergraduate Multicultural Education course. The study included 20 participants. Students completed service-learning lesson plans using Backward Design (Wiggins \& McTighe, 2005). Of the 20 lesson plans, 17 used Backward Design (Wiggins \& McTighe, 2005) to develop content-specific lesson plans. Furthermore, Stiler (2009) determined that the use of "overarching understanding and essential questions from Backward Design (Wiggins \& McTighe, 2005) helped facilitate the development of lessons" (p. 117). 
Graff (2011) sought to determine the efficacy and usefulness of Backward Design (Wiggins \& McTighe, 2005) on teacher practice. Backward Design (Wiggins \& McTighe, 2005) was taught in an undergraduate Curriculum and Instruction education course from 2004-2006. Thirty former students participated in a focus group. Of the 30 participants, 26 eluded to the helpfulness of Backward Design (Wiggins \& McTighe, 2005) on feeling prepared for curriculum and planning. According to the results, $65 \%$ specifically stated Backward Design (Wiggins \& McTighe, 2005) helped in their preparation to plan. Additional findings showed that planning with the end in mind helped new teachers design and evaluate instruction (Graff, 2011).

Although respondents discussed positive feelings towards Backward Design (Wiggins \& McTighe, 2005) they also expressed Backward Design as "an effective and agonizing way to learn" (Graff, 2011, p. 164). The process was "agonizing" (Graff, 2011, p.164) in the sense that students were often left without answers to specific best practices to use. Instead, Backward Design (Wiggins \& McTighe, 2005) helped pre-service teachers decide the best practices to use for particular contexts and students. This supports the claim that teachers must plan with their students' interests and needs in mind. Moreover, respondents considered the process "agonizing" (Graff, 2011, p. 164) because of the content knowledge required to plan. As Shulman (1986b) discussed PCK cannot occur without sound content knowledge. Overall, the study demonstrated that Backward Design (Wiggins \& McTighe, 2005) helped pre-service teachers feel prepared when planning instruction.

From the discussed studies (Kelting-Gibson, 2005; Stiler, 2009; Graff, 2011) the use of Backward Design (Wiggins \& McTighe, 2005) helped teachers develop curriculum with the end goal in mind and focus instruction on specific information to teach. Beginning with the end in mind helped teachers focus on the curriculum outcomes, not on activities of the unit (Shumway \& Berret, 2004). Based on the above-mentioned features, teachers and planners can predict the weaknesses of their students. Moreover, it helped them focus instruction on the content taught and provided an avenue to ensure alignment between the desired results, assessments, and instructional activities. They were able to plan more standards-based instruction, as opposed to activity-based instruction. By focusing on the standards, teachers created more purposeful instruction for students.

According to Wiggins and McTighe (2005), "Teaching is a means to an end. Having a clear goal helps to focus our planning and guide purposeful action toward the intended results" (p. 19). Backward design calls for educators to make goals or standards specific and concrete in terms of assessment evidence, as educators begin to plan each lesson, unit, or course. Fisher and Frey (2007) concurred with Wiggins and McTighe (2005) that checking for student understanding in the classroom influences the educator's ability to select appropriate materials and opportunities for teaching and learning outcomes, such as tossing a coin. Fisher and Frey concluded that "when teachers regularly check for understanding, students become increasingly aware of how to monitor their own understanding" (p. 3).

Jackson (2009) stated that a teacher's mindset "is a way of thinking about instruction, about students, about learning, and about teaching in general that makes teaching fluid, 
efficient, and effective" (p. 2). She determined that good educators focus on knowing what questions to ask rather than having all of the answers. As a result of each lesson, educators formulate questions that are relevant and sufficient. Finally, assessment information is appropriately utilized to achieve desired results.

Hodaeian and Biria (2015) had a threefold in the context of Iranian foreign language learning. First, they aimed to determine whether the application of backward design model has any significant effect on reading comprehension of intermediate EFL learners. Second, their study sought to evaluate the merits of backward design, if any, over forward design in teaching reading comprehension. Finally, they tried to identify learners' attitudes toward teaching L2 reading comprehension through the backward design. As such, a mixed method research design with several stages was utilized. A Quick Placement Test (QPT) was administered to the population of 150 female students studying English as a foreign language at a private institute. Based on the results of the test, 60 intermediate students were chosen and randomly assigned to two samples (30 each); namely, control and experimental groups. During the treatment, the control group received the reading instruction through a conventional method of forward design, while the participants in the experimental group were taught by the backward design. Both control and experimental samples were homogenized based on learners' responses to a needs analysis questionnaire as well as a reading comprehension pre-test. At the end of the treatment, a reading comprehension post-test was administered. The results suggested that backward design had significantly impacted learners' reading comprehension skill. Accordingly, it was concluded that backward design can enhance reading comprehension of Iranian EFL learners remarkably. Notably, the respondents' answers to the attitude questionnaire also substantiated the superiority of backward design over conventional forward designs used for teaching reading comprehension.

Berk and Ünal (2017) aimed to determine sixth, seventh and eighth grade students' writing anxiety and dispositions and to examine to what extent they predict each other. The basis of this study is to determine whether writing disposition is the significant predictor of writing anxiety or not and whether students' grade levels and genders are significant predictor of writing anxiety and dispositions or not. The research was designed according to survey model. The study group, selected through simple sampling method, is made up of 860 students studying at 6th, 7th and 8th grades in elementary schools of Sarkisla District, Sivas. While "Writing Anxiety Scale", adapted into Turkish by Özbay and Zorbay (2011), was administered to determine the study group's writing anxiety level, "Writing Disposition Scale", adapted into Turkish by Iseri and Ünal (2010), was used to determine the writing disposition level. At the end of the study, it was found that writing disposition is a significant predictor of writing anxiety and students' grade levels and genders are significant predictors of writing anxiety and dispositions.

Daniel et al. (2017) examined familiarity with and usage of "Understanding by Design" (UbD) among music teacher educators. They mention that UbD (Wiggins \& McTighe, 2005) provides a curricular approach for the revised National Standards for Music Education as part of the National Coalition for Core Arts Standards. Accordingly, the 
co-authors collected quantitative and qualitative data to examine how music teacher educators conceptualized and implemented UbD. Initially, 300 members of the National Association for Music Education (NAfME) served as participants and responded to an online survey. Responses indicated a low level of understanding UbD, some frustration with communication about the revised standards, and an interest in creating a UbD resource network for music educators. As a follow-up, 13 participants who had experience of using aspects of $\mathrm{UbD}$ in their teaching volunteered for semi-structured interviews. From those data, four themes emerged: curricular modeling, awareness and advocacy, teacher mindset, and pedagogical disadvantages of UbD. Implications include responsive professional development to explain and promote $\mathrm{UbD}$ in terms of its role in the revised standards. Additionally, music teacher educators may find a repository of sample UbD formatted lesson plans useful in understanding and using the revised national standards.

In another recent study Bowen (2017) has studied the benefits of using backward design and mentions:

"Our lessons, units, and courses should be logically inferred from the results sought, not derived from the methods, books, and activities with which we are most comfortable. Curriculum should lay out the most effective ways of achieving specific results... in short, the best designs derive backward from the learnings sought."

Furthermore Daniela and Derek (2017) examined the why, what and how of teaching from the perspective of teaching engineering design in an integrative learning environment. Why the guiding is vision and relates to why one reads or studies particular topics. It is the starting point of the learning process. Once why has been established, a backward design approach is utilized to formulate the what and how. What relates to the development of discipline-specific skills and competencies? The what for engineering design is considered from the perspective of the ability to a) generate new design solutions; b) improve existing design solutions; and c) manage design. How is the creative strategy that effectively supports transformative learning and can involve three other ws; namely, who, when and where. Successful engineering design education requires the active participation of students in all stages of the educational process.

Shanthi et al. (2018) investigated the effect of writing centre consultations on the essay writing skills of L1 Arabic foundation level students at an English-medium university in the Gulf region. Analysis was based on quantitative measures of writing ability of two distinct groups of students: an experimental group who participated in tutoring sessions at the university's writing center and a control group who did not. Findings indicated that students who participated in writing center consultations scored significantly higher in overall essay writing scores, as well as in two aspects of writing: task fulfilment (that is ideas) and text organization/coherence. Their findings contribute to a limited bank of similar empirical studies on effectiveness of writing center sessions on students' essay writing ability. They also support the case for the expansion of writing center work beyond the domains of predominantly L1 English academic communities. 
Abadikhah et al. (2018) investigated EFL university students' attitude towards selfregulated learning strategies in writing academic papers. A further aim of their study was to compare the attitudes of two groups of university students (third and fourth years) in the employment of self-regulated learning strategies to find out whether academic education assists students to become more self-regulated writers with the passage of time. A questionnaire was developed and administered to 98 college students majoring in English language. The questionnaire consisted of 60 items assessing six dimensions of self-regulated learning, namely, motive, method, time, physical environment, social environment, and performance. Descriptive analyses revealed that the participants were moderate to slightly high in the use of self-regulatory strategies and processes. Furthermore, the findings indicated that certain writing strategies including pre-writing, goal-setting and self-consequence were not appropriately employed by the participants, this is suggesting an important need to acquire additional strategies for their writing. Using independent samples t-tests, we found that the fourth year students more frequently employed self-regulatory learning strategies in writing (i.e. method and social environment) than did the third year students in this study.

\section{METHOD}

\section{Participants}

The study population was 100 Iranian EFL learners in Gooyesh Language Institute, Isfahan, Iran. Random sampling was employed to select the participating language learners because the participants were supposed to be at the same level. After obtaining agreement from both the Institute principals and English teachers, preliminary arrangements were made and dates were set. The participating students' age ranged from 18 to 25 . Finally the participants were randomly assigned to two groups namely, namely as control and experimental groups, each comprised of 50 participants.

\section{Instruments}

Different instruments were used to provide appropriate responses to the abovementioned research questions. To identify the proficiency level of the participants Quick Placement Test (QPT, version 1) was used. The test as shown in attachment consists of two parts; part one consists 40 questions testing situations (five questions), cloze passages- testing prepositions, grammar, pronouns, and vocabulary- (15 questions), and completion questions (20 questions). The second part contains 20 questions: 10 questions on cloze passages and 10 questions of completion type questions. All questions are multiplechoice items. Speaking tasks simulating 'natural' situations were used in the pre and post-tests to elicit usage of communication strategies, which might be affected by training. Such communicative tasks were viewed by Nunan (1989 cited in Mitsuko, 2009) as an effective way to not only help language learners in the classroom but also to help researchers examine the acquisition of the target language. Brown (1991 cited in Mitsuko, 2009) claims that the opportunity and the need to exchange information in turn leads to negotiating of meaning and mutual understanding, an ideal context for using CSs:

'Two-ways tasks' is the term used for tasks in which both participants (in a dyad) and all participants (in a group) process some but not all of information they need 
to resolve the task, and so, while everyone is able to contribute information, everyone also needs to get some information'.

As the dependent variable of the study in hand was IELTS writing ability, two versions of IELTS Task 1 Writing assessment criteria (band descriptors - public version) were used as the pre- test and the post- test to check students' IELTS writing ability in the three groups. Regarding the assessment, two examiners (raters) assessed writings on the 4 marking criteria used for the assessment of IELTS writing tasks (established by British Council, university of Cambridge, ESOL examinations) including task achievement, cohesion and coherence, lexical resource (vocabulary) and grammatical range and accuracy. Each criterion is worth $25 \%$ of the total marks for the IELTS writing tasks. Since the study used a pretest-posttest design, one version of IELTS Writing Task 1 was used as the pre-test and another version as the post-test. It is imperative to mention that the structure of the pretest-posttest design was similar to what is conducted in a formal IELTS writing exam.

\section{Procedure}

In order to observe and interpret a wide range of behaviors, including even minor nonverbal ones in the classes under observation, a high level of preparation was required. This necessitates piloting the observation scheme to ensure the validity and reliability of the measures.

In the piloting stage of the study, two different single-gender male classes including 64 IELTS candidates (aged from 18 to 25, with a mean of 21.5) at Gooyesh language institute were observed and the newly developed questionnaires were administered at the end of each session. While students were filling out the questionnaires, their comments regarding the wordings, ordering, or ambiguities of the items was sought. In addition, the observed teachers were consulted to ensure that the marking the observational items match the actual classroom behaviors. Consequently, some of the items in the questionnaires were modified and the teachers' ideas helped fine-tune the questionnaires and the observation scheme. The completion of the questionnaires lasted about 10 minutes and the standard class time was 90 minutes.

Then the placement procedures were conducted in order to place participants in relevant groups. To do so, all the participants took the QPT placement test and based on the results of the tests, they were placed in two groups of control (conventional training) and experimental (backward training), each with 50 IELTS candidates. It should be mentioned that at the beginning of the course, all participants became familiar with the IELTS exam, in general and the speaking module in particular. It is imperative to mention that out of the 36 sessions of the IELTS course, 8 sessions to speaking module in which both the General Training and Academic Modules candidates participated.

In order to answer the first research question concerning the relationship between the application of backward design teaching approach and the improvement of writing skill of Iranian EFL learners with an intermediate proficiency level, the oral interview and Pre/Post-test Speaking Tasks were run. In order to see if the classification is reliable and 
the specified groups represented truly different motivation groups, an independent samples $t$-test was run.

In order to answer the second question that is superiority of backward design to conventional forward models in the improvement of writing ability of Iranian EFL learners after assigning the students into experimental and control groups, each group was taught as specified (i.e. for the experimental group using backward design and for the control group traditional models was implemented). In the next step inside each group statistical analysis was done for each of the results of scores obtained using the posttest scores of the IELTS writing tasks. Then the results of each skill were compared for the two groups by running a $t$ test. Regarding the classification of teachers to be assigned as backward design, teachers compared the backward design with conventional forward model for the measurement of the improvement of writing ability of Iranian EFL learners with intermediate proficiency level. The Independent variable formulated in this research is backward design and the dependent variable is intermediate EFL learners' writing ability. The regular use of assessment is essential in the backward design model (Wiggins \&McTighe, 2005). The study was done in two phases of descriptive and experimental. Qualitative research procedures were applied for data collection as well as qualitative-quantitative procedures for data analysis, specifically processing, analyzing, and coding of the collected qualitative data, as well as subsequent quantification and interpretation of the coded data based on the principles of backwarddesigned curriculum as advanced by Grant Wiggins and Jay McTighe in their publication, Understanding by Design.

Regarding the two important measures of validity including internal vs. external validity it should be mentioned that internal validity is a way to measure if research is sound (i.e. was the research done right?). It is related to how many confounding variables you have in your experiment. If an experiment is run and confounding variables are avoided, the internal validity is high; the more confounding variables are present in the research, the lower the internal validity. In a perfect world, the experiment would have a high internal validity. This would allow the researcher to have high confidence that the results of your experiment are caused by only one independent variable. So as the seemingly ideal results including availability of an experiment and only one independent variable are apparent in this study, it seems that the internal validity is comparatively high.

On the other hand, external validity is the validity of generalized (causal) inferences in research, usually based on experiments as experimental validity. In other words, it is the extent to which the results of a study can be generalized to other situations and to other people. Mathematical analysis of external validity concerns a determination of whether generalization across heterogeneous populations is feasible and devising statistical and computational methods that produce valid generalizations. In this regard generalization of the results should be done more cautiously.

\section{Data Analysis Procedure}

The data gathered through the questionnaires and the interviews were tabulated to make them easy for application. All the statistical procedures were conducted by the SPSS 
software version 22. Moreover, the data were analysed qualitatively and the answers were considered with scrutiny to find out the differences between the scores of students in backward design vs. traditional design classes.

\section{FINDINGS}

\section{Findings for Research Question One}

The first research question of the study was an attempt to find out whether backward design teaching approach improve the writing ability of Iranian EFL learners at an intermediate proficiency level or not; for this purpose, the writing pre-test and post-test scores of the learners in the EG were compared by means of a paired-samples $t$ test, as shown in Tables 1 and 2 below:

Table 1

Results of Descriptive Statistics Comparing the Writing Pre-test and Post-test Scores of the EG Learners

\begin{tabular}{lllll}
\hline & $\mathrm{N}$ & Mean & Std. Deviation & Std. Error Mean \\
\hline Pre-test & 50 & 4.66 & .65 & .09 \\
Post-test & 50 & 5.09 & .51 & .07 \\
\hline
\end{tabular}

Table 1 shows that the EG learners could obtain the mean scores of 4.66 on the pre-test of writing and 5.09 on the writing post-test. In order to find out whether the difference between these two Means scores was statistically significant or not, the researcher needed to consult the paired-samples $t$ test table (Table 2):

Table 2

Results of Paired-Samples $t$ Test Comparing the Writing Pre-test and Post-test Scores of the EG Learners

\begin{tabular}{|c|c|c|c|c|c|c|c|c|c|}
\hline & & \multicolumn{5}{|c|}{ Paired Differences } & \multirow{3}{*}{$t$} & \multirow{3}{*}{$d f$} & \multirow{3}{*}{$\begin{array}{l}\text { Sig. } \\
(2- \\
\text { taile } \\
\text { d) }\end{array}$} \\
\hline & & \multirow[t]{2}{*}{ Mean } & \multirow[t]{2}{*}{$\begin{array}{l}\text { Std. } \\
\text { Deviation }\end{array}$} & \multirow[t]{2}{*}{$\begin{array}{l}\text { Std. } \\
\text { Error } \\
\text { Mean }\end{array}$} & \multicolumn{2}{|c|}{$\begin{array}{l}95 \% \text { Confidence } \\
\text { Interval of the } \\
\text { Difference }\end{array}$} & & & \\
\hline & & & & & Lower & Upper & & & \\
\hline $\begin{array}{l}\text { pre-test } \\
\text { post-test }\end{array}$ & - & -.43 & .35 & .04 & -.52 & .33 & $-\overline{8.68}$ & $\begin{array}{l}4 \\
9\end{array}$ & .00 \\
\hline
\end{tabular}

In Table 2, the $p$ value under the Sig. (2-tailed) column was found to be smaller than the significance level $(p<.05)$, so it could be inferred that the EG learners experienced significant improvements in their scores from writing pre-test to writing post-test, indicating the effectiveness of backward design teaching approach in boosting the writing ability of the EFL learners.

\section{Findings for Research Question Two}

The second research question of the study asked: Is backward design teaching approach pedagogically superior to conventional forward models in the improvement of productive skills of Iranian EFL learners at intermediate proficiency level? To attain this aim, the researcher had to compare the speaking post-test scores of the EG and CG learners, for which an independent-samples $t$ test could be conducted. However, to 
control for any possible pre-existing differences between these two groups on the speaking pretest, and compare their post-test scores accordingly, one-way ANCOVA was conducted. The analyses performed for speaking are separately presented in the following subsections.

\section{Writing in Focus}

Regarding the comparison of the EG and CG in terms of their writing post-tests, the descriptive statistics results could be seen in Table 3 and the ANCOVA results appeared in Table 3:

Table 3

Descriptive Statistics for Comparing the Writing Post-test Scores of the EG and CG Learners

\begin{tabular}{llll}
\hline Groups & Mean & Std. Deviation & $N$ \\
\hline EG & 5.09 & .51 & 50 \\
\hline CG & 4.99 & .42 & 50 \\
\hline Total & 5.04 & .46 & 100 \\
\hline
\end{tabular}

Table 4.3 displays the fact that the writing post-test mean score of the EG learners $(M=$ $5.09)$ was larger than the writing post-test mean score of the CG learners $(M=4.99)$. To figure out whether this difference between the writing post-test mean scores of the two groups was a statistically significant one or not, the researcher had to examine the $p$ value under the Sig. column in front of the Groups row in Table 4 below:

Table 4

Results of One-Way ANCOVA for Comparing the Writing Post-test Scores of the EG and CG Learners

\begin{tabular}{lllllll}
\hline Source & $\begin{array}{l}\text { Type III Sum of } \\
\text { Squares }\end{array}$ & $d f$ & Mean Square & $F$ & Sig. & $\begin{array}{l}\text { Partial } \\
\text { Squared }\end{array}$ \\
\hline Corrected Model & 13.00 & 2 & 6.50 & 71.38 & .00 & .59 \\
\hline Intercept & 7.83 & 1 & 7.83 & 86.02 & .00 & .47 \\
\hline Pre-test & 12.75 & 1 & 12.75 & 140.01 & .00 & .59 \\
\hline Groups & .25 & 1 & .25 & 2.74 & .10 & .02 \\
\hline Error & 8.83 & 97 & .09 & & & \\
\hline Total & 2562.00 & 100 & & & & \\
\hline Corrected Total & 21.84 & 99 & & & & \\
\hline
\end{tabular}

The $p$ value corresponding to the Groups row of the above table equalled .10, which is greater than the alpha level of significance (i.e., .10 > .05). This indicates that the difference between the writing post-test mean scores of the two groups of EG $(M=5.09)$ and CG $(M=4.99)$ was not of statistical significance. In other words, it could be inferred that using backward design teaching approach failed to be more effective than traditional instruction as far as L2 writing ability of Iranian EFL learners is concerned.

\section{DISCUSSION}

This study aimed at investigating the influence of adopting backward design for improving Iranian advanced EFL learners' writing skills. Wiggnis and McTighe (2006) believe teachers are designers. So they should craft the curriculum and learning experiences to meet specified purposes. Teachers are also designers of assessments to 
recognize student needs to guide their teaching and to enable themselves and their students to determine whether they have achieved their goals. In designing the course, they should be mindful of their student interests, developmental levels, large classes, and previous achievements in order to shape their thinking about the learning activities, assignments, and assessments. Accordingly, the present study was designed as a experimental research design which involved language learners at intermediate level. The study population was 100 Iranian EFL learners in Gooyesh Language Institute, Isfahan, Iran. In the preceding parts the research questions are discussed in detail and are compared with studies that had done in the field of the raised questions.

\section{CONCLUSION}

As defined by Wiggins and McTighe, Understanding by Design is a "framework for designing curriculum units, performance assessments, and instruction that lead students to deep understanding of the content teachers teach," UbD expands on "six facets of understanding", which include students being able to explain, interpret, apply, have perspective, empathize, and have self-knowledge about a given topic.

To consider the effects of backward design on the students writing skill, the level of writing ability of the experimental and control groups' students before and after training was compared. Results of data analysis showed using backward design teaching approach failed to be more effective than traditional instruction as far as L2 writing ability of Iranian EFL learners is concerned.

The findings of the study were in contrast with those of Hodaeian and Biria (2015) who aimed to determine whether the application of backward design model has any significant effect on reading comprehension of Iranian intermediate EFL learners.

Furthermore, backward design teaching approach was pedagogically and significantly superior to conventional forward models in the improvement of Iranian EFL learners' writing ability. The findings of this research are in line with Saengchan et al. (2016) pilot research in which they investigated the effectiveness of using learning centered techniques to enhance the performance of backward design, by using an effectiveness index (E.I.) and to study the extent of satisfaction of students using student-centered teaching methods to enhance the performance of backward design. The finding of their study indicated a high level of effectiveness in terms of student learning and performance through implementation of backward design. Students satisfied with learning from the teaching plans from English instructional design through storytelling at the very satisfaction $(x=4.56)$ that is higher than the criterion given at the satisfactory level.

\section{REFERENCES}

Abadikhah, S.; Aliyan, Z. \& Talebi, S. H. (2018). EFL students' attitudes towards selfregulated learning strategies in academic writing. Issues in Educational Research, 28(1), 2018 
Berk, R. \& Ünal, E. (2017). Comparison of Writing Anxiety and Writing Dispositions of Sixth, Seventh and Eighth Grade Students. International Journal of Instruction, v10 n1 p237-254 Jan 2017

Bobbitt, F. (2004). Scientific method in curriculum-making. In Flinders, D.J., \& Thornton, S.J. (Eds.), The curriculum studies (9-16). New York, NY: Routledge.

Bowen, S. (2017). Understanding by Design. Vanderbilt University Center for Teaching. Retrieved [todaysdate] from https://cft.vanderbilt.edu/understanding-bydesign/.

Brown, R. (1991) Group Work, Task Difference, and Second Language Acquisition. Applied Linguistics, 12 (1), 1-12

Daniel, J.;Amber, P.; Amy, S. \& Johnathan, V. (2017). Investigating “Understanding by Design" in the national music education standards: Perspectives and practices of music teacher educators. Visions of Research in Music Education, 30. Retrieved from http://www.rider.edu/ vrme

Daniela, P. \& Derek, N. (2017). The why, what and how of teaching: an engineering design perspective. Global Journal of Engineering Education. Volume 19, Number 2, 2017

Danielson, C. (1996). Enhancing professional practice: A framework for teaching. Alexandria, Virginia: Association for Supervision and Curriculum Development.

Henderson, J.G. \& Gornik, R. (2007). Transformative curriculum leadership. Upper Saddle River, NJ: Pearson Education, Inc.

Hinchliffe, L. J. (2016). Instructional Design for Literacy: Using the "Understanding by Design" Model to Achieve Learner Success. Available online at:

https://iflasatellitetampere2012.files.wordpress.com/2012/08/session6b_hinchliffe.pdf

Fisher, D. \& Frey, N. (2007). Checking for understanding: formative assessment techniques for your classroom. Alexandria, VA: Association for Supervision and Curriculum Development.

Florian, A.; Timothy, P. \& Zimmerman, Jay P. (2015). Understanding by Design, Moodle, and Blended Learning: A Secondary School Case Study. Merlot Journal of Online Learning and Teaching Vol. 11, No. 1, March. P.P: 120-128

Graff, N. (2011). “An effective and agonizing way to learn:” Backwards design and new teachers' preparation for planning curriculum, Teacher Education Quarterly, 151- 168.

Hodaeian, M. \& Biria, R. (2015). The effect of Backward Design on Intermediate EFL Learners' L2 Reading Comprehension: Focusing on Learners' Attitudes. Journal of Applied Linguistics and Language Research Volume 2, Issue 7, 2015, pp. 80-93 Available online at www.jallr.ir ISSN: 2376-760X

Kelting-Gibson, L.M. (2005). Comparison of curriculum development practices. Educational Research Quarterly. 29(1), 26-36. 
Macdonald, J.B., \& Purpel, D.E. (1987). Curriculum and planning: Visions and metaphors. Journal of Curriculum and Supervision, (2)2, 178-192.

McTighe, J. (2013). LDC and UbD: Complementary Frameworks. Revised January 6.

Published by Funding the Bill \& Melinda Gates Foundation, London.

Mitsuko, N. (2009) The effects of the use of communication and negotiation strategies on L2 acquisition. Thesis, University of Iowa

Nunan, D. (1989) Designing Tasks for the Communicative Classroom. Cambridge: Cambridge University Press.

Pinar, W. (2006). The synoptic text today and other essays. New York, NY: Peter Lang Publishing, Incorporated.

Richards, J. (2013). Curriculum approaches in language teaching: forward, central and backward design. Australia: Sage.

Saengchan, K.; Kriangsak, S. \& Prakong Y. (2016) The Performance of Backward Design Using Student- Centered Teaching Methods on the Bachelor of English Education Students, Roi Et Rajabhat University, Thailand. Conference Proceedings. The 8th Thailand-Japan International Academic Conference 2016

Schwab, J.J. (1969). The practical: A language for curriculum. The School Review, (78) 1, 1-23.

Scruggs, T. E., Mastropieri, M. A., \& McDulfie, K. A. (2007). Co-teaching in inclusive classrooms: A metasynthesis of qualitative research. Exceptional Children, 7, 392-41.

Shanthi, T.; Alistair, R.; Elizabeth, W. \& Tom, N. (2018). Measuring the Effectiveness of Writing Center Consultations on L2 Writers' Essay Writing Skills. Languages 2018, 3, 4; doi: 10.3390/languages3010004

Shulman, L.S. (1986b). Those who understand: Knowledge growth in teaching. Educational Researcher 15(2), 4-14.

Shumway, S., \& Berrett, J. (2004). Standards-based curriculum development for preservice and in-service: A "partnering" approach using modified backwards design. The Technology Teacher, 26-29.

Stiler, G. (2009). Planning to serve: Using backwards planning to design servicelearning lesson plans in the preservice curriculum. Journal on Excellence in College Teaching, (20)2, 105-123.

Stufflebeam et al., (1985). An Analysis of Alternative Approaches to Evaluation

Wiggins, G. \& McTighe, J. (2005). Understanding by Design: Expanded Second Edition. Alexandria, VA: ASCD.

Wiggins, G., \& Mctighe, J. (2006). Understanding by design (2nd Ed.). Alexandria, Virginia, USA: ASCD product.

Wiggins, G., \& Mctighe, J. (2011). The Understanding by Design guide to creating highquality units. Alexandria, VA: ASCD. 